\title{
ANALYSIS OF THE FACTORS AFFECTING THE DECISION MAKING PROCESS OF RECRUITMENT AND SELECTION OF STRATEGIC POSITIONS
}

\author{
Prof. MSc. Alexis Olmedo \\ Industrial Engineer \\ Andres Bello University \\ Santiago, RM, Chile \\ E-mail: alexis.olmedo@gmail.com; aolmedo@unab.cl \\ Paolo Herrera Manriquez \\ Industrial Engineer \\ Santiago, RM, Chile \\ E-mail: paolo.herrera@toteck.cl \\ Felipe Rojas Rojas \\ Industrial Engineer \\ Santiago, RM, Chile \\ E-mail: frojasr@udla.cl \\ Michael Olivares Maturana \\ Electrical Engineer \\ Santiago, RM, Chile \\ E-mail: michael_olivares@hotmail.com
}

\begin{abstract}
This paper presents the results of an exploratory study that analyzes the main factors of the decision making process of recruitment and selection of strategic positions for companies located in Santiago of Chile, in the Metropolitan Region of Chile. The methodology developed uses AHP Multi-criteria concepts, addressing the major theoretical foundations of this methodology. The results of a survey of organizations in Santiago city, in order to obtain the similarities and the most relevant factors for the recruitment and selection of strategic positions, are presented, allowing the establishment of an exploratory common pattern for the process.
\end{abstract}

Keywords: AHP, process, recruitment, HR, Business Organizations, Intellectual Capital 


\section{Introduction}

Globalization has made it so that innovation, entrepreneurship, creativity, and speed to adapt quickly to change, to new knowledge and trends are essential (Ganga \& Sanches, 2008), showing that for the achievement of goals it is required to have staff with the necessary attitudes, knowledge and skills (Gerrero \& Narvaez, 2013), called strategic qualities.

These strategic qualities have become a reference for managing people Delobbe et al. (2014) obtained through a process of comparison and decision in which there are many uncertainties involved Arza et al. (2012), commonly referred to as "staff selection and recruitment process". This process, if done incorrectly, can affect efficiency, innovation and the competitiveness of the organization (Ganga \& Sanches, 2008) becoming a fundamental pillar to achieving the objectives.

In this context, this paper aims to establish, in an exploratory manner, a common guide of the predominant factors for the decision process of seclusion and selection of strategic staff, based on Analytic Hierarchy Process method (AHP), which will be supported by the implementation of surveys, interviews and focus groups from different organizations.

\section{Literature Review}

So that the process of staff selection is optimal, implementation of a tool that allows an evaluation, classification and weighing of the top candidates to select is necessary (Zolfani \& Antucheviciene, 2012), highlighting the methodology Analytical Hierarchy Process (AHP) developed by Thomas Saaty (1980), to facilitate the resolution of complex problems of multiple criteria.

This hierarchical model according to Castro et al. (2013) \& Golden and Wasil (2003) is developed through:

Identification of the problem to be solved; Defining the objective that will serve to improve the situation; Identification of sub-criteria that are relevant aspects that significantly affect the objectives; Finally the identification of alternatives, proposals being feasible solutions to the problem.

To Beynon (2002) an advantage of applying the AHP methodology is that "assessments where qualitative factors exist are allowed, weights are assigned to each of the elements, which are used as decision criteria, and the use of computers is allowed to drive the analysis and accuracy of the results". Another advantage of using AHP methodology is emphasized by the fact that, among the decision-making members of a work team, it facilitates communication between them, reaching greater consensus between the parties (Harker \& Vargas, 1987).

Nonetheless, in this model, the decision-maker must clearly explain, through their judgment, the importance of each of the criteria in the target set Gracía et al. (2006) managing to measure how each element contributes to the next higher hierarchy level. 
IJAHP Article: Mu, Saaty/A Style Guide for Paper Proposals To Be Submitted to the International Symposium of the Analytic Hierarchy Process 2014, Washington D.C., U.S.A.

\section{Hypotheses/Objectives}

This exploratory study has the purpose of determining the common factors that affect the decision making process of recruitment and selection of strategic positions in companies located in Santiago, Chile. To achieve this objective the following specific objectives have:

- Review and analysis of the state of the art methodology AHP

- Preparation, identification and development of surveys and interviews

- Determination of predominant factors of personal choice

- Exploratory Discussion of the results

\section{Research Design/Methodology}

The development and implementation of surveys and interviews were the underpinnings of the process of gathering information for the development of this document. 185 businesses in the municipality of Santiago, Chile, composed of micro, small, medium and large firms, were considered. For the calculation of sample collection of the companies surveyed, a confidence level of $95 \%$ was employed, a standard deviation of $5 \%$ and an error of $5 \%$ resulting in a sample of $n=126$ businesses was used.

The implementation of the surveys and interviews are mainly divided into the development of open questions and alternatives, in order to understand the factors and variables that affect the process of selection and recruitment. In addition, it was considered not to use technical terms where possible, and the reliability of respondents and interviewees.

Similarly, to corroborate that information, a focus group made up of 50 companies and individuals from all levels of the organization was conducted (strategic, medium and operating) chosen at random from the companies surveyed and interviewed.

Finally it is established, by analysing the study realised, the dependencies of the relationships of the factors, variables and similarities that affect the choice of hiring based on strategic personnel AHP methodology, based on the structure shown in Figure 1 
Figure 1

AHP Methodology Proposal Process

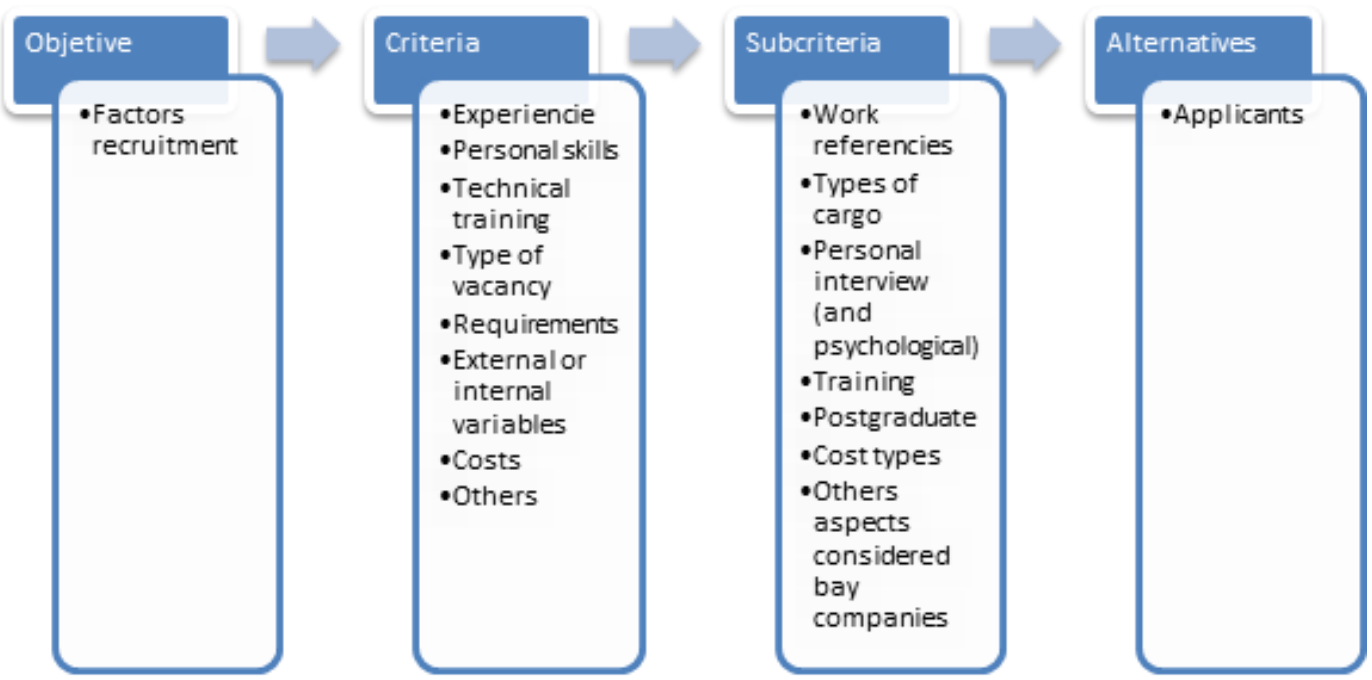

\section{Data/Model Analysis}

\subsection{Results of the Study}

According to the study, and as reflected in Table 1, there are three main criteria: work experience (33\%), personal skills (37\%) and academic training received (30\%).

Also, the criteria of work experience consists of two sub-criteria: employment references of previous work (33\%) and types of previous positions $(67 \%)$. For the criterion of personal skills 2 subcriteria emerge: the result obtained in a personal interview (67\%) and the results of psychological testing (33\%) and, finally, for the criterion of academic training three subcriteria emerge: formal education made up of undergraduate studies $(50 \%)$, training-specialization $(12 \%)$ and postgraduate studies referred mainly to personal-professional growth of each person (38\%).

It is noted that making a definitive decision for one of the alternatives (corresponding to the applicants), the surveyed companies define a shortlist in order to establish the "final" candidate selected, mainly because personal skills in executive positions have significant predominance for the award of such fees. 
IJAHP Article: Mu, Saaty/A Style Guide for Paper Proposals To Be Submitted to the International Symposium of the Analytic Hierarchy Process 2014, Washington D.C., U.S.A.

Table 1

Importance of Evaluation Factors in Selection and Recruitment process personal

\begin{tabular}{cccc}
\hline Critera & Priority & Subcriterion & $\begin{array}{c}\text { Importance of } \\
\text { Evaluation }\end{array}$ \\
\hline experience & $33 \%$ & $\begin{array}{c}\text { Employment References } \\
\text { Types of Cargo }\end{array}$ & $33 \%$ \\
& & Outcome interview & $67 \%$ \\
\hline Personal & $37 \%$ & Psychological Test Result & $33 \%$ \\
Skills & \multirow{3}{*}{$30 \%$} & Formal education & $50 \%$ \\
\hline \multirow{2}{*}{ Academic } & Training Course & $12 \%$ \\
Background & & Graduate & $38 \%$ \\
\hline
\end{tabular}

\subsection{Análisis y Discusión del Estudio}

The results of this exploratory study make clear that in the recruitment and selection of strategic personnel, the only ability or skill that cannot be acquired are soft skills, given that leadership, effective communication, high performance team development, crisis management, and organizational changes are mainly inherent in the subject and are very difficult to acquire.

Regarding academic training, it is established, that if the candidate has experience, this is not as important, due to the fact that it can be acquired through mechanisms of personal and professional development, however, it appears that for the process of selection and recruitment of strategic positions it is inherent experience (know how).

Regarding the applicants, these are alternative solutions to a particular problem or need, with high volatility, mainly because they depend on the results obtained in the different stages of the recruitment and selection process.

This is why the process of selection and recruitment of personnel in strategic positions should focus on finding people who are able to inspire, mobilize the various business teams and themselves in order to go beyond business, markets and the situation itself.

Therefore an integrated understanding of the environment and human networks is not only needed, but also, the process of recruitment and selection of staff is viewed from a balanced prism between the strategic and operational approaches, and not so single operating as was reflected at the beginning of this research. 
IJAHP Article: Mu, Saaty/A Style Guide for Paper Proposals To Be Submitted to the International Symposium of the Analytic Hierarchy Process 2014, Washington D.C., U.S.A.

\section{Limitations}

There are two limitations in the proposed methodology. First it is established that the criteria and sub-criteria in place focus on strategic positions overall, excluding specific position profiles and special criteria for a particular selection, however, it is noted that further studies based on profiling and charges lead to include new relationships.

A second limitation of the methodology has been identified in the alternatives because this item is excluded in the previous selection to determine the short list chosen for the final selection. A solution to this problem is based on a study and analysis of integration in this model from the previous selection of candidates in the short list, obtaining a better overview about the candidates and establishing a more robust model.

\section{Conclusions}

This exploratory study makes it clear that the main factors and variables (criteria and subcriteria) to be used in the process of recruitment and selection strategic personnel, establishing a common standard for this type of process.

In a similar fashion, it is established by companies that the applicability of the methodology is understandable, easy to use and is an effective tool for use in recruitment and selection dilemmas of strategic position staff.

Finally, the results given in this paper aim to develop future studies in the recruitment and selection through AHP methodology or other lke ANP.

\section{Key References}

Arza Pérez, L., Verdecia Martínez, E., \& Lavandero García, J. (2012). El empleo de metodos de toma de decisión y técnicas de soft computing en la selección de personal. Revista Cubana de Ciencias Informáticas, 6(3), 1-14.

Beynon, M. (2002). DS/AHP method: A mathematical. European Journal of Operational Research 140, 148-164.

Castro, A., García , J., Sifuentes de la Hoya, E., \& Linares, M. (2013). Estudio del Estado del arte de las aplicaciones de Analytic Hierarchy Process. Cultura Científica y Tecnologica, 10(51), 144-164.

Delobbe, N., Gilbert, P., \& Le Boudela, M. (2014). Gérer des compétences: une instrumentation en contexte, modélisation fondée sur l'étude de cas (French). Industrial Relations, 69(1), 28-59.

Ganga, F., \& Sánches, R. (2008). Estudio sobre el proceso de reclutamiento y seleccion de personal en la comuna de Puerto Montt, Región de los Lagos-Chile. Gaceta Laboral, 271-297. 
IJAHP Article: Mu, Saaty/A Style Guide for Paper Proposals To Be Submitted to the International Symposium of the Analytic Hierarchy Process 2014, Washington D.C., U.S.A.

Gerrero, C., \& Narváez, G. (2013). Las competencias: Una propuesta conceptual hacia la unificación miltidimensional en el contexto de los Recursos Humanos. European Scientific Journal, 4, 391-402.

Gracía, J., Noriega, S., \& Díaz, J. (2006). Aplicacion del procesdo de Jerarquía Analítica en la selección de Tecnología Agrícola. Agronomia Costarricense 30, 107-114.

Harker, P., \& Vargas, L. (1987). The theory of ratio scale estimation: Saaty's Analytic Hierarchy Process. Management Science 33, 1383-1403.

Saaty, T. (1980). The Analytic Hierarchy Process. New York: McGraw-Hill.

Wasil E., \& Golden B. (2003). Celebrating 25 years of AHP-based decision making. Computers and Operations Research 30, 1419-1420.

Wasil E., \& Golden B. (2003). Celebrating 25 years of AHP-based decision making. Computers and Operations Research 30, 1419-1420.

Zolfani, S., \& Antucheviciene, J. (2012). Team Member Selecting Based on AHP an TOPSIS Grey. Enguneering Economics, 23(4), 425-434. 